\title{
Global estimates of carbon stock changes in living forest biomass: EDGARv4.3 - time series from 1990 to 2010
}

\author{
A. M. R. Petrescu ${ }^{1}$, R. Abad-Viñas ${ }^{2}$, G. Janssens-Maenhout ${ }^{1}$, V. N. B. Blujdea ${ }^{2,3}$, and G. Grassi ${ }^{2}$ \\ ${ }^{1}$ DG Joint Research Centre - European Commission, Institute for Environment and Sustainability (IES) Air and Climate Unit, \\ Via Enrico Fermi 2749, 21027 ISPRA (VA), Italy \\ ${ }^{2}$ DG Joint Research Centre - European Commission, Institute for Environment and Sustainability (IES) Forest Unit, \\ Via Enrico Fermi 2749, 21027 ISPRA (VA), Italy \\ ${ }^{3}$ Forest Research and Management Institute, B-dul Eroilor 128, 077190 Voluntari (Ilfov), Romania
}

Correspondence to: A. M. R. Petrescu (roxana.petrescu@jrc.ec.europa.eu)

Received: 27 January 2012 - Published in Biogeosciences Discuss.: 26 March 2012

Revised: 4 July 2012 - Accepted: 25 July 2012 - Published: 30 August 2012

\begin{abstract}
While the Emissions Database for Global Atmospheric Research (EDGAR) focuses on global estimates for the full set of anthropogenic activities, the Land Use, Land-Use Change and Forestry (LULUCF) sector might be the most diverse and most challenging to cover consistently for all countries of the world. Parties to United Nations Framework Convention on Climate Change (UNFCCC) are required to provide periodic estimates of greenhouse gas (GHG) emissions, following the latest approved methodological guidance by the International Panel on Climate Change (IPCC). The current study aims to consistently estimate the carbon (C) stock changes from living forest biomass for all countries of the world, in order to complete the LULUCF sector in EDGAR. In order to derive comparable estimates for developing and developed countries, it is crucial to use a single methodology with global applicability. Data for developing countries are generally poor, such that only the Tier 1 methods from either the IPCC Good Practice Guide for Land Use, Land-Use Change and Forestry (GPG-LULUCF) 2003 or the IPCC 2006 Guidelines can be applied to these countries. For this purpose, we applied the IPCC Tier 1 method at global level following both IPCC GPG-LULUCF 2003 and IPCC 2006, using spatially coarse activity data (i.e. area, obtained combining two different global forest maps: the Global Land Cover map and the eco-zones subdivision of the Global Ecological Zone (GEZ) map) in combination with the IPCC default $\mathrm{C}$ stocks and $\mathrm{C}$ stock change factors. Results for the $\mathrm{C}$ stock changes were calculated separately for gains, harvest, fires (Global Fire Emissions Database ver-
\end{abstract}

sion 3, GFEDv.3) and net deforestation for the years 1990, 2000, 2005 and 2010. At the global level, results obtained with the two sets of IPCC guidance differed by about $40 \%$, due to different assumptions and default factors. The IPCC Tier 1 method unavoidably introduced high uncertainties due to the "globalization" of parameters. When the results using IPCC 2006 for Annex I Parties are compared to other international datasets such as (UNFCCC, Food and Agriculture Organization of the United Nations (FAO)) or scientific publications, a significant overestimation of the sink emerges. For developing countries, we conclude that $\mathrm{C}$ stock change in forest remaining forest can hardly be estimated with the Tier 1 method especially for calculating the $\mathrm{C}$ losses, mainly because wood removal data are not separately available on harvesting or deforestation. Overall, confronting the IPCC GPG-LULUCF 2003 and IPCC 2006 methodologies, we conclude that IPCC 2006 suits best the needs of EDGAR and provide a consistent global picture of $\mathrm{C}$ stock changes from living forest biomass independent of country estimates.

\section{Introduction}

Large uncertainties exist on the magnitude of the global effect of forests on atmospheric $\mathrm{CO}_{2}$ concentration. For the 90s, the International Panel on Climate Change (IPCC, 2007) indicates a global terrestrial net sink of $-1.0+0.6 \mathrm{Gt} \mathrm{C} \mathrm{yr}^{-1}$, comprising a net source of $+1.6(+0.5$ to +2.7$) \mathrm{Gt} \mathrm{C} \mathrm{yr}^{-1}$ from land-use changes and a residual terrestrial sink of -2.6 


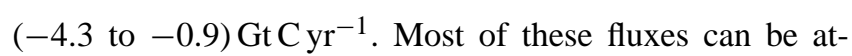
tributed to forests. More recently, Pan et al. (2011) estimated

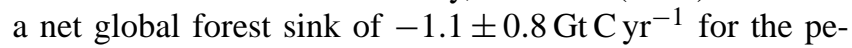
riod 1990-2007, comprising a source of $+2.9 \pm 0.5 \mathrm{Gt} \mathrm{C} \mathrm{yr}^{-1}$ from gross deforestation and a sink of $-4.0 \pm 0.7 \mathrm{GtC} \mathrm{yr}^{-1}$ from established forests and from the regrowth of forests after past deforestation and logging. The large uncertainty on these numbers is among the reasons for the partial inclusion of the emissions and removals from the Land Use, Land-Use Change and Forestry (LULUCF) sector in the commitments by industrialized countries (Annex I) under the Kyoto Protocol (KP). The recent developments in UNFCCC (United Nations Framework Convention on Climate Change) negotiations with regard to both LULUCF and a mechanism for reducing emissions from deforestation and forest degradation (REDD) in developing countries (Non-Annex I Parties) will certainly increase the attention on the need to estimate C stock changes from forests (sinks/sources) in a consistent way for all countries.

An accurate estimation of these emissions can help in better understanding the impacts on future climate change and the potential of different mitigation options (Lu et al., 2002). Remotely sensed data of high spatial resolution are possibly most suitable to estimate the biomass spread over large areas, but remain scarce. Due to increasing greenhouse gases (GHGs) in the atmosphere, it is essential to know and monitor changes in the amount of forest land (Iverson et al., 1994). Other studies focused mainly on C losses from deforestation, land-use conversions and forest fires (Houghton, 2002, 2010; van der Werf, 2009) or the effect of socio-political changes on land-use pattern in Eastern Europe (Olofsson et al., 2009). As a result of combining different sources and information on forestry and land-use change, during the last years several vegetation/ecological maps were created Global Land Cover Map (GLC 2003) GlobCover 300 m, FAO Global Ecological Zones, United States Geological Survey- Global land Cover Characterization (USGS-GLCC, The Global Land Cover by National Mapping Organizations (GLCNMO), GlobCover 2009). Even before the UNFCCC and KP came into force, other legally binding mechanisms such as the Ramsar Convention, UN Convention for Biological Diversity and the International Tropical Timber Agreement fostered supranational collaboration between countries aiming at collectively protecting forests, fighting deforestation and illegal logging, and monitoring the GHG levels. Associated with these processes are online databases like the IPCC Good Practice Guidance for Land Use, Land-Use Change and Forestry (GPG-LULUCF) 2003 and IPCC 2006 databases, where biomass expansion factors (BEFs) and other parameters can be found.

Parties to UNFCCC are required to provide periodic estimates of GHG emissions, following the latest approved methodological guidance by the IPCC. While Annex I Parties report on a yearly basis their GHG emissions LULUCF, the current rules foresee only a periodic reporting by Non-
Annex I Parties. For the first commitment period of the KP (2008-2012), Annex I Parties follow the IPCC GPGLULUCF 2003. With the recent approval by UNFCCC of the IPCC 2006 Guidelines, the use of IPCC 2006 will become the standard for Annex I Parties after 2012, and it will likely become a relevant source of information to be used by Non-Annex I Parties. The overall approach provided by the IPCC to estimate $\mathrm{C}$ stock changes in a given $\mathrm{C}$ pool is essentially the same in the IPCC GPG-LULUCF 2003 and in the IPCC 2006, i.e. estimates can be obtained either through the "gain-loss" method (i.e. sum of all gains and losses) or the "stock-difference" method (i.e. difference between C stocks at two points in time); a system of three tiers of increasing methodological complexity is also provided. However, some difference exists between the IPCC GPG-LULUCF 2003 and the IPCC 2006, e.g. the latter contains some updated values and/or improved assumptions in the default Tier 1 method. Therefore, it is of great importance to know the potential impact of using either IPCC GPG-LULUCF 2003 or IPCC 2006 on the estimates of $\mathrm{C}$ stock changes.

With the Emissions Database for Global Atmospheric Research (EDGAR) of European Commission-Joint Research Centre/Planbureau voor de Leeformgeving (EC-JRC/PBL, 2011), all anthropogenic emissions for all countries of the world are mapped using consistently the same bottom-up methodologies such that country- or sector-specific shares can be compared. To extend the LULUCF sector of EDGAR, the carbon $(\mathrm{C})$ stock changes from living forest biomass are calculated under a similar approach respecting the EDGAR requirements on consistent geocoverage, using the two IPCC methodologies IPCC GPG-LULUCF 2003 and the IPCC 2006. The most suitable for EDGAR is the methodology that provides consistently for all countries of the world estimates at the common denominator of level of detail, at least Tier 1. For this purpose, we applied the IPCC Tier 1 method at global level, i.e. using spatially coarse activity data (i.e. area, obtained combining two different global forest maps) in combination with the IPCC default emission/removal factors (i.e. C stock change per unit of area). The resulting database of $\mathrm{C}$ stock changes in living forest biomass, representing the main source of emissions and removals from the land-use sector at global level, will be included in the EDGAR database version 4.3. The forthcoming EDGAR v4.3 is an extension of the bottom-up inventory EDGAR v4.2 (EC-JRC/PBL, 2011) with a completion for the human-made biogenic GHGs, Organic Carbon (CO) and Black Carbon (BC) trends from 1970-2008 for all countries of the world, derived with the same technologybased methodology and following IPCC and European Monitoring and Evaluation Programme/European Environmental Angecy (EMEP/EEA) international standard values and references. The database is unique because of its global coverage (geospatial, sectorial and chemical) and its consistency, with minimized biases between countries and sectors and constraint by global closure. While the use of the 
Tier 1 method for estimating $\mathrm{C}$ stock changes in living forest biomass certainly introduces larger uncertainties than higher tiers, the added value of the paper is the global consistency of the resulting estimates and the highlight of the differences in results when using the Tier 1 method and the IPCC GPGLULUCF 2003 or IPCC 2006.

\section{Material and methods}

Estimates of net $\mathrm{C}$ stock changes in living forest biomass frequently suffer in accuracy. For forest land remaining forest land, the challenge is given by the large bidirectional fluxes of $\mathrm{CO}_{2}$ from/to the atmosphere, i.e. the net change is often a small difference between two large numbers. For land-use changes from/to forests, the main challenge is estimating accurately the area affected and its average $\mathrm{C}$ stock. In line with EDGAR's approach of estimating bottom-up with international statistics and published parameters for each country of the world, this study computed the $\mathrm{C}$ stock changes in living forest biomass following the Tier 1 method. For this purpose, for each country the "gain-loss" method was used for forest remaining forest, using the IPCC default values for the gains (i.e. forest growth), as provided in the IPCC GPG methodology (IPCC, 2003) and in the IPCC 2006 Guidelines (IPCC, 2006), and using the mean default values and data from Food and Agriculture Organization Statistics Division (FAOSTAT) for harvest (Forest products production, import and export statistics, ForesSTAT) and from the Global Fire Emissions Database GFEDv.3 for fire emissions (van der Werf et al., 2010). Consistent global country-specific estimates of C stock changes for the Land Use, Land-Use Change and Forestry LULUCF sector were obtained separately for gains, harvest, fires and net deforestation for the years 1990, 2000, 2005 and 2010. In this study the activity data (forest land area) was estimated for all the countries and climatic regions using a combination of satellite maps on land-use cover and vegetation type (see Sect. 2.2). The year 2000 was used as starting point, and changes in forest area from 2000 to 1995 and from 1995 to 1990 backwards in time and from 2000 to 2005 and 2005 to 2010 forward in time were calculated based on the share of forest area change reported by FAO Global Forest Resources Assessements (FRA) 2010 reports.

\subsection{Dataset structure}

The dataset consists of four different $\mathrm{C}$ stock change categories: gains, harvest, fires and net deforestation. All of them were calculated (except fires) following the IPCC GPGLULUCF 2003 and IPCC 2006 Guidelines. The gains are presented with a negative sign as they correspond to a sink. A comparison between results was performed in order to detect the best available methodology for EDGAR's purpose. For the definition of the subcategories, we follow as much as possible the IPCC guidelines but noticed slight methodological

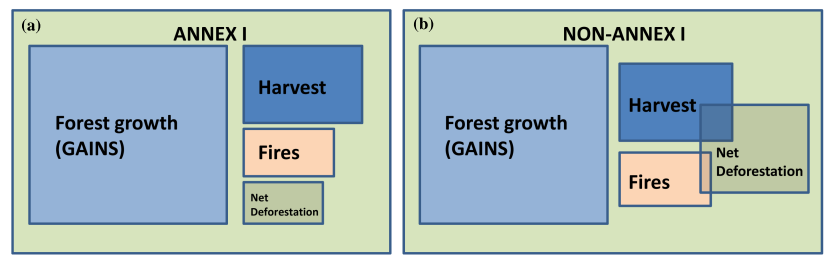

Fig. 1. Representation of assumptions made in the calculation of the $\mathrm{C}$ stock changes for (a) Annex I and (b) Non-Annex I Parties to UNFCCC, when taking into account the gains and losses.

differences between IPCC 2006 and IPCC GPG-LULUCF 2003 (see Sects. S1 and S2 in the Supplement). By gains we mean gross annual increase in biomass $\mathrm{C}$ stocks (i.e. forest growth), by harvest annual $\mathrm{C}$ losses due to harvest, by fires $\mathrm{C}$ losses due to forest fires and by net deforestation annual losses in $\mathrm{C}$ due to deforestation calculated with the stock change method.

For a better understanding of our results and the assumptions we made, we are using the diagrams (Fig. 1a, b) to illustrate the differences between Annex I and Non-Annex I Parties, and to show why we kept the split of four categories and why we avoided their combination to net global totals. Figure 1a, b shows the assumptions made in calculating the $\mathrm{C}$ stock changes in Annex I and Non-Annex I Parties. We assume that for Annex I Parties (Fig. 1a) the four categories do not overlap, i.e. the losses due to harvest or fire are quite well separated from the losses due to deforestation. Therefore, the total net emissions can be calculated as a sum of gains, harvest, fires and deforestation because of the very low probability of omitting or double-counting. Contrary to this, Fig. 1b shows different ways in which changes can be affected depending on how the balance is done. It is risky to perform a net total, as we do not know if harvest, fires or deforestation overlay each other (e.g. if fires occurred in a deforested area or in a harvested area or in both); even limits of emissions or removals could be nevertheless derived for each country.

\subsection{Available international statistics}

\subsubsection{GLC 2000 map}

The Global Land Cover (GLC) map was developed by the European Commission Joint Research Centre's Global Environment Monitoring Unit in collaboration with worldwide partners (GLC, 2003). It provides a harmonized classification of the land cover at $0.5^{\circ} \times 0.5^{\circ}$ resolution comprising 23 classes (GLC, 2003). Only the first 6 classes were used to compute the forest area for each country, as they define tree cover under forest definition (see the Supplement, Table S1).

\subsubsection{FAO Ecological zone (GEZ) map}

This map was developed by the Food and Agriculture Organization of the United Nations (FAO) to meet the 
requirements of the Forest Resources Assessment (FAO, 2000) reporting process. FAO's Global Ecological Zone (GEZ) classification relies on a combination of climate and potential vegetation. It was first developed by Zhu (1997) and Preto (1998). For the choice of climatic parameters to be used in the FAO (2000) map, a number of global zones/areas were surveyed, including Köppen (1931) modified by Trewartha (1968) and Holdridge (1947) (FAO, 2000). Table S1 provides an overview of vegetation classes as defined by the GEZ map, which were currently used to calculate the forest area.

\subsubsection{ForesSTAT}

FAO through its database FAOSTAT provides time series of data related to food and agriculture for some 200 countries. ForesSTAT is part of FAOSTAT and contains data and detailed information for the forestry sector. The forest product statistics on harvest were used to compute the $\mathrm{C}$ stock changes (losses) for the years 1990, 2000, 2005 and 2010 (FAOSTAT-FAO, 2011).

\subsubsection{GFEDv.3}

The $\mathrm{C}$ losses from forest fires are based on GFEDv.3 data (van der Werf et al., 2010). They were calculated by multiplying the burned biomass estimates with the carbon fraction of each forest type (tropical, temperate). This fire dataset consists of a modelling framework that utilises satellite data on vegetation characteristics and productivity to estimate fuel loads combined with satellite-derived burned area to estimate fire emissions (GFEDv.3, 2012). It consists of $0.5^{\circ} \times 0.5^{\circ}$ gridded monthly fire emissions from 1997 to 2010. EDGAR is using already the GFEDv. 2 data in reporting greenhouse gas emissions from forest fires, and the following version EDGAR v4.3 will incorporate GFEDv.3.

\subsection{Applied methodologies}

\subsubsection{IPCC GPG-LULUCF 2003}

The Good Practice Guidance for Land Use, Land-Use Change and Forestry (GPG-LULUCF) is a report of IPCC requested by the UNFCCC to provide countries with a supplementary methodology and guidance for measuring, monitoring, estimating and reporting on $\mathrm{C}$ stock changes and GHG emissions from LULUCF activities (IPCC, 2003). Its main aim is to assist countries in producing national GHG inventories for the LULUCF sector and present the choices in GHG estimation methodology for all C pools and GHG sources. The current study uses the methodology described in Chapter 3, Sect. 3.2, point 3.2.1 and complemented by the Annex 3A.1 - Biomass default values for Forest Land. The IPCC GPG-LULUCF 2003 provides sufficient information and data to allow a Tier 1 estimate of various emissions at the country scale. The step-by-step methodology is presented in the Supplement, Sect. S1, where the changes and variations from original formulas are explained.

\subsubsection{IPCC 2006 Guidelines}

The IPCC 2006 provides in its Chapter 4 - Forest Land, guidance for preparing annual greenhouse gas inventories for the forestry sector. It builds on the Revised 1996 IPCC Guidelines for National Greenhouse Gas Inventories (1996 IPCC Guidelines) and the IPCC GPG-LULUCF 2003. This approach is intended to improve consistency and completeness in the estimation and reporting of greenhouse gas emissions and removals (IPCC, 2006). The current study uses the methodology described in Sect. 4.2 and complemented by the tables in Sect. 4.5, which provides methods for estimating the $\mathrm{C}$ changes, sources and sinks of GHGs for forest land remaining forest land. The step-by-step methodology is presented in the Supplement, Sect. S2, where the changes and variations from original formulas are explained.

\section{Results}

We compare the results for $\mathrm{C}$ stock changes calculated with both IPCC GPG-LULUCF 2003 and IPCC 2006 methodologies after we first present our results in a global perspective and compare them with the available global datasets: FRA (2010), UNFCCC (2011) and Pan et al. (2011) (Table 1).

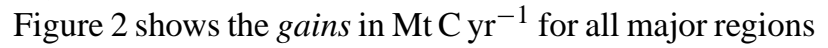
of the world as a comparison between the two methodologies.

Figure 3 presents the $\mathrm{C}$ stock losses from harvest in $\mathrm{MtC} \mathrm{yr}^{-1}$ for all major regions of the world as a comparison between IPCC GPG-LULUCF 2003 and IPCC 2006.

To highlight major differences between allocation of different parameters in the two calculations (above-ground biomass and Biomass Conversion and Expansion Factors (BCEF), see the Supplement, Tables S3 and S4, respectively), Table 2 presents the different stratification of ecozones and vegetation (i.e. forest) types used by the two guidelines. We should notice that (1) the climatic zone "subtropical" from IPCC 2006, which is in particular of high occurrence in Non-Annex I Parties, was not present in IPCC GPG-LULUCF 2003, and (2) IPCC 2006 has more vegetation types addressed separately.

Figure 4 presents the $\mathrm{C}$ stock losses from fires in $\mathrm{Mt} \mathrm{C} \mathrm{yr}^{-1}$ for all major regions of the world. A comparison between the two IPCC methodologies cannot exist because they use the same data from GFEDv.3 (van der Werf et al., 2010; GFEDv.3, 2012).

Figure 5 presents the $\mathrm{C}$ stock losses from net deforestation in $\mathrm{Mt} \mathrm{C} \mathrm{yr}^{-1}$ for all major regions of the world as a comparison between IPCC 2003 and 2006. 
Table 1. Global estimates of $\mathrm{C}$ stock changes in $\mathrm{GtC} \mathrm{yr}^{-1}$ calculated with IPCC 2006 Tier 1 and compared with other available global estimates. IPCC 2006 calculates net deforestation. UNFCCC and FRA 2010 report only net $\mathrm{C}$ stock changes.

\begin{tabular}{|c|c|c|c|c|c|c|}
\hline Region & Source & Category & 1990 & 2000 & 2005 & 2010 \\
\hline \multirow[t]{8}{*}{ Annex I } & Tier 1 & G & -1.57 & -1.59 & -1.59 & -1.60 \\
\hline & (IPCC, 2006) & $\mathrm{H}$ & 0.67 & 0.64 & 0.68 & 0.60 \\
\hline & & $\mathrm{F}$ & 0.08 & 0.14 & 0.11 & 0.16 \\
\hline & & net D & 0 & 0 & 0.02 & 0.05 \\
\hline & & total & -0.82 & -0.81 & -0.79 & -0.79 \\
\hline & FRA 2010 & total & -0.23 & -0.24 & -0.29 & -0.32 \\
\hline & $\begin{array}{l}\text { UNFCCC } 2011^{\mathrm{b}} \\
\text { (managed forests) }\end{array}$ & total & -0.34 & -0.34 & -0.33 & -0.40 \\
\hline & $\operatorname{Pan}^{\mathrm{a}}$ & total & \multicolumn{2}{|c|}{$-0.39^{c}$} & \multicolumn{2}{|c|}{$-0.44^{\mathrm{d}}$} \\
\hline Non- & Tier 1 & $\mathrm{G}$ & -2.37 & -2.28 & -2.24 & -2.21 \\
\hline \multirow[t]{3}{*}{ Annex 1} & (IPCC, 2006) & $\mathrm{H}$ & 2.38 & 2.72 & 2.84 & 2.90 \\
\hline & & $\mathrm{F}$ & 0.23 & 0.11 & 0.13 & 0.12 \\
\hline & & net D & 1.3 & 1.3 & 1.24 & 1.17 \\
\hline
\end{tabular}

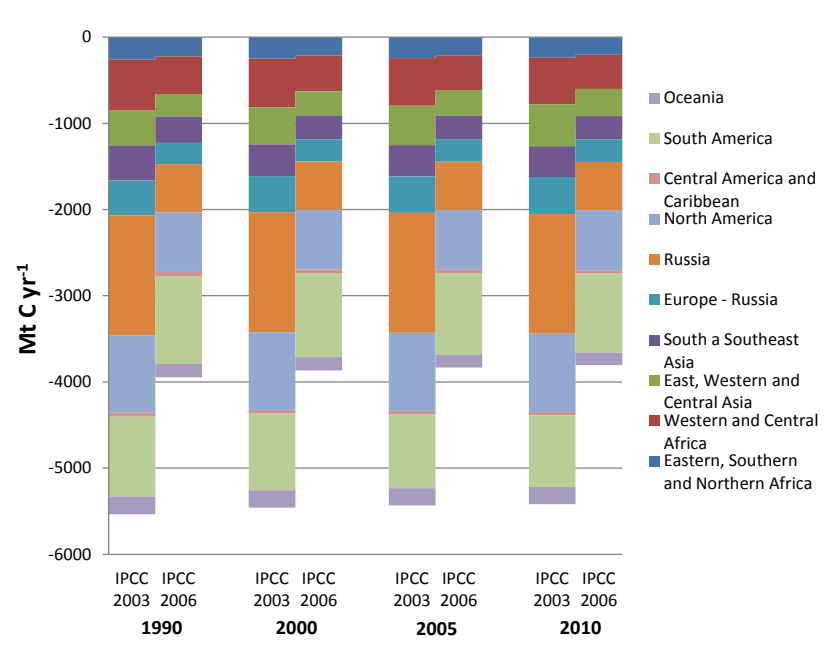

Fig. 2. Comparison of $\mathrm{C}$ stock gains in $\mathrm{MtC} \mathrm{yr}^{-1}$ between IPCC GPG-LULUCF 2003 and IPCC 2006 for major regions of the world.

In Fig. 6 we plotted the results for gains in tons $\mathrm{CO}_{2}$, which will be included in the EDGAR v4.3 database, representing the absolute difference between $\mathrm{CO}_{2}$ stock change in 2000 and 2010, having as proxy the distribution of the trees computed after GLC 2000 map classes 1-6 (Supplement, Table S1). Positive values represent a higher $\mathrm{CO}_{2}$ removal in 2000 compared to 2010, while negative values show an increase in $\mathrm{CO}_{2}$ removal in 2010 compared to 2000.

\section{Discussion}

As shown in Figs. 2, 3 and 4, there is a systematic overestimation of IPCC GPG-LULUCF 2003 calculations in comparison to IPCC 2006, and overall the differences can be critical for the majority of regions of the world.

The method for area estimation in the current work implements a definition which is not likely consistent with countries' definitions applied in GHG inventories or in FAO reports but shows the results under hypothetically harmonized forest definition across borders. Our method practically assesses the "net of forest area under land cover definition" in the year 2000 as seen by satellites, contrary to e.g. the national GHG inventory of Annex I Parties or FRA 2010, where "forest land" is generally included under forestry use (thus including areas with temporary loss of forest cover). With this method the forest area is determined at a certain moment in time (i.e. the assessment years) based on the land cover approach, which is the best proxy for the total area of "forest land remaining forest land" and any potential "expansion of forest or reforestation/afforestation" and estimation of the sink or annual $\mathrm{CO}_{2}$ removal /emissions from living forest biomass in that specific year, which is EDGAR's purpose. Obviously there is an area of regrowth (after wood harvesting) and afforestation/reforestation, but this cannot be easily detected by our static method of accounting. If we assume that deforestation is a land cover change from forest to non-forest, then our method is likely to provide conservative estimates of emissions because of including areas of early stages of regrowth (whose actual fate is not yet known). To these differences, $20 \%$ uncertainty is added (i.e. GLC, 2003, 
Table 2. Differences in climatic zones and vegetation types between IPCC 2006 and IPCC 2003.

\begin{tabular}{|c|c|c|c|}
\hline \multicolumn{2}{|r|}{ IPCC 2006} & \multicolumn{2}{|r|}{ IPCC GPG-LULUCF 2003} \\
\hline Climatic zone & Vegetation type & Climatic zone & Vegetation type \\
\hline \multirow[t]{5}{*}{ Tropical } & Tropical rain & Tropical & Wet \\
\hline & Tropical moist deciduous & & Moist with short or long dry season \\
\hline & Tropical dry forest & & Dry \\
\hline & Tropical shrubland & & \\
\hline & Tropical mountain systems & & Montane moist or montane dry \\
\hline \multirow[t]{4}{*}{ Subtropical } & Subtropical humid forest & Tropical* & Moist with short or long dry season \\
\hline & Subtropical dry forest & & Tropical dry \\
\hline & Subtropical steppe & & \\
\hline & Subtropical mountain systems & & Tropical montane moist or montane dry \\
\hline \multirow[t]{3}{*}{ Temperate } & Temperate oceanic forest & Temperate & Coniferous \\
\hline & Temperate continental forest & & Broadleaf \\
\hline & Temperate mountain systems & & Mixed broadleaf-coniferous \\
\hline \multirow[t]{3}{*}{ Boreal } & Boreal coniferous forest & Boreal & Coniferous \\
\hline & Boreal tundra woodland & & Forest - Tundra \\
\hline & Boreal mountain systems & & Mixed broadleaf-coniferous \\
\hline
\end{tabular}

* No Subtropical class in IPCC GPG-LULUCF 2003.

map compared with The Moderate Resolution Imaging Spectroradiometer (MODIS) harmonizing the legend, Fritz and See, 2005). Moreover, MODIS has 75-80\% global accuracy (Hodges, 2002) and in addition the forest average certainty reported by Fritz and See (2008) is 0.557 (55\%) and adds an uncertainty of $45 \%$.

Due to the different availability and types of data at national level, countries show freely varying implementations of the agreed guidelines. As original data and time series were originally designed for forestry, the appropriateness for a national GHG inventory could be rather limited. Further on, suitability of historic data for emission reduction compliance purposes is also questionable (and as such the ability to establish an accurate historical base inventory, like the one from 1990). Consistency among international reporting frames is requested for GHG inventories with the words "each Party shall justify in its reporting that such values are consistent with the information that has historically been reported to the FAO or other international bodies, and if they differ, explain why and how such values were chosen" (so-called Marrakesh Accords, UNFCCC, 2001). Difference in the land data availability is fully reflected in the UNFCCC reporting obligation for full land reporting by Annex I Parties and partial reporting of land-use change and forestry-related removal or sources by Non-Annex I Parties. Under these circumstances, the reportings of Annex I and Non-Annex I Parties are difficult to compare in practice (see Fig. 1).

While assessing the global estimates based on default values from the two IPCC guidelines (assuming same activity data), the comparison of these results with other available global data sources and estimates is difficult, some- times nonsensical. Major differences derive from inconsistent definitions of forest/forest land and parameters collected under various underlying methodologies involved. Regarding FRA (2010) we notice that the estimates account only for net changes, and a split between gains and losses is not possible to be made. Under the assumption of complementary between the categories, we could give a global estimate of all net $\mathrm{C}$ changes "gain-loss" from our IPCC 2006 results, but only for Annex I, mounting to a net average global C change of $-0.80 \mathrm{GtC}$ (1990-2010), representing an approx. factor two difference with FRA 2010 averaged estimate of $-0.27 \mathrm{GtC},-0.41 \mathrm{GtC} \mathrm{yr}^{-1}$ of Pan et al. (2011) and $-0.35 \mathrm{Gt} \mathrm{C} \mathrm{yr}^{-1}$ for UNFCCC (2011). We also see that our IPCC 2006 average estimate of total global C gain (living forest biomass) for the four years is $-1.9 \mathrm{GtC}$, while Pan et al. (2011) (see Table 2, column "Biomass" in Pan et al., 2011) report an averaged 1990-2007 gain from biomass of $-2.9 \mathrm{GtC}$. The main difference between all above-mentioned estimates is that the current study neither accounts for $\mathrm{C}$ gained from forest regrowth nor $\mathrm{C}$ lost from disturbances (i.e. diseases). Regarding deforestation, Pan et al. (2011) estimate a gross budget from tropical regions, which includes the gain from regrowth of forests because the $\mathrm{C}$ uptake by tropical regrowth forests is implicitly included in commonly estimated net emissions of tropical land-use changes, rather than to estimate it independently as a sink. Our average estimate for net deforestation of $0.6 \mathrm{GtC}$ (1990-2010) fits well within the range of these publications (Table 1). 


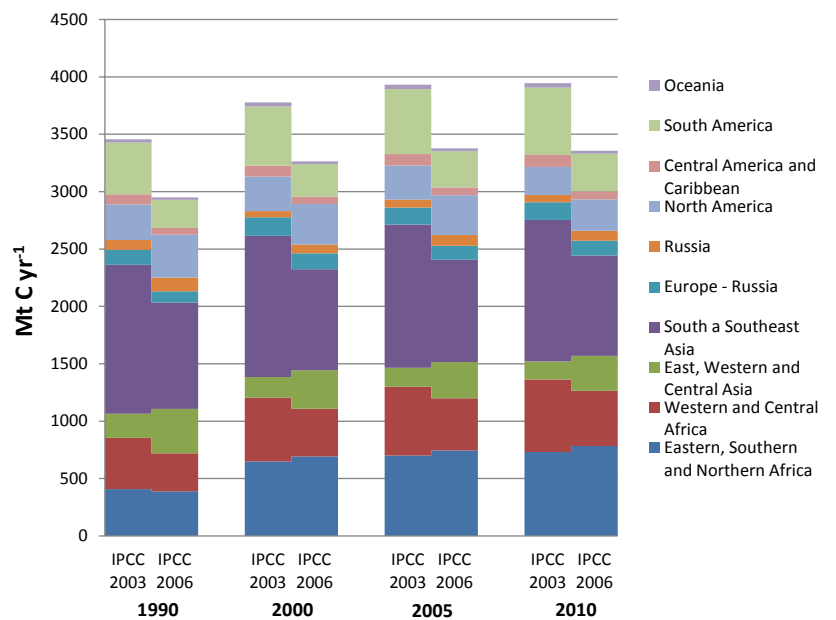

Fig. 3. Comparison of $\mathrm{C}$ stock losses - harvest in $\mathrm{Mt} \mathrm{C} \mathrm{yr}^{-1}$ between IPCC GPG-LULUCF 2003 and IPCC 2006 for major regions of the world.

\subsection{Breakdown and analysis for critical issues in comparing IPCC GPG-LULUCF 2003 and IPCC 2006 estimates}

\subsubsection{Carbon gains in living forest biomass}

The quality of proxies for $\mathrm{C}$ stock change estimations is mainly affected by outdated data assumed to be valid for the year 2000 (IPCC, 2003), which are the data used for present estimation. In the IPCC GPG-LULUCF 2003, $28 \%$ of data come from forest inventory (apparently $60 \%$ of the countries in Africa have integral or partial forest inventories). For the rest of the countries, the specific source is not mentioned, but for Annex I Parties data obviously originate from their forest inventories. IPCC default data are given as "mean value and as the range of possible values", which may be heavily biased by limited references especially poor for NonAnnex I Parties. IPCC provides breakdown values on each biomass component. Furthermore, assumptions behind estimation with IPCC default values are crucial, as controversial results may occur; for instance, when modelling Canadian forest for a certain period, the results ranged from sink to source by either including or not the natural disturbances (Greenough et al., 1997).

Available default parameters in the IPCC Annex 3.A.1 tables of IPCC GPG-LULUCF 2003, recommended to be used by countries when applying Tier 1 for EDGAR, were used in this study. Key to the major difference between the two methodologies and one of the inconsistencies we identified between IPCC 2006 and IPCC GPG-LULUCF 2003 was the inclusion in 2003 of $R$ (root to shoot parameter), which is the ratio of below-ground to above-ground biomass. IPCC GPGLULUCF 2003 included this parameter in its calculation of annual increment in biomass (Supplement, Eq. 1), while IPCC 2006 assumes no changes in below-ground biomass

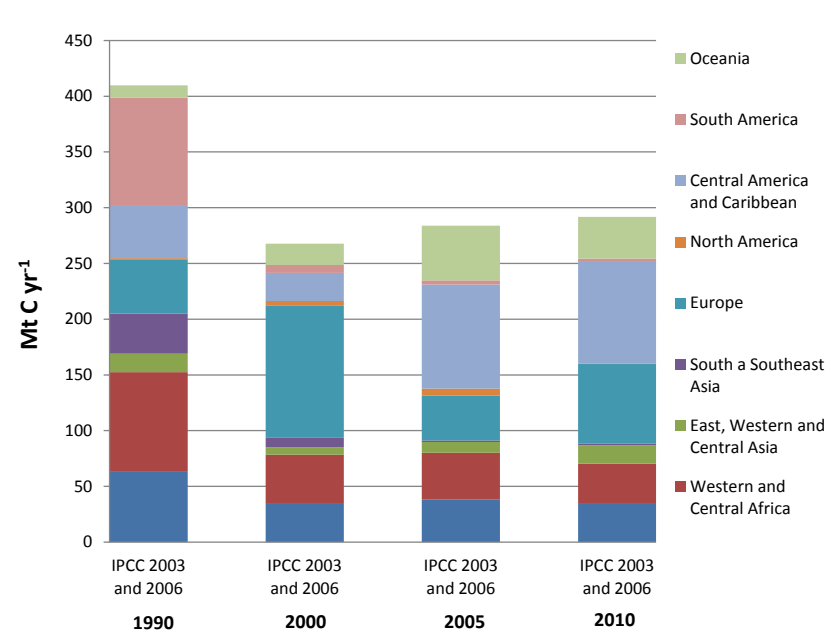

Fig. 4. $\mathrm{C}$ stock losses - fires in $\mathrm{Mt} \mathrm{C} \mathrm{yr}^{-1}$, based on GFEDv.3 (van der Werf et al., 2010) used for calculating $C$ losses from fires for both IPCC GPG-LULUCF 2003 and IPCC 2006 methodologies.

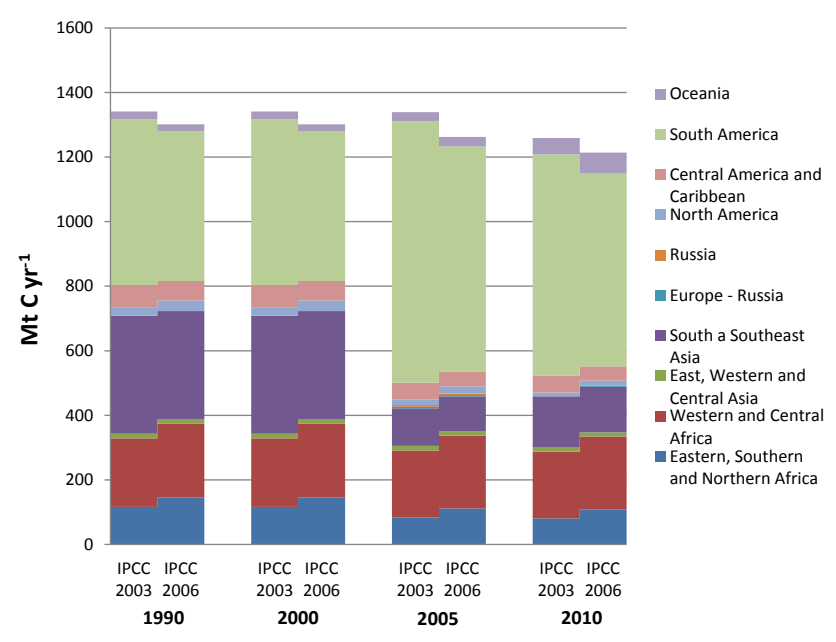

Fig. 5. Comparison of $\mathrm{C}$ stock losses - net deforestation in

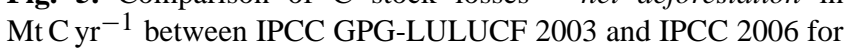
major regions of the world.

allocation pattern and is set for Tier 1 at zero. The explanation is the likeliness that below-ground biomass remains as part of the dead organic matter and decomposes slowly (unlike above-ground biomass, which has a significant potential to decompose immediately). According to IPCC GPGLULUCF 2003, for the Tier 1 approach, no change of belowground biomass is assumed. This accounts for $30 \%$ difference (uncertainty) in total gains between the two approaches (Fig. 2). Regarding this matter we notice that IPCC 2006 is consistent in using $R$ (applied to harvest losses too, Supplement, Eq. 10), while IPCC GPG-LULUCF 2003 is using it only for the gains. Another minor difference is the use of carbon fraction (CF), which in 2003 is set at 0.5 while in 2006 it is 0.47 . 


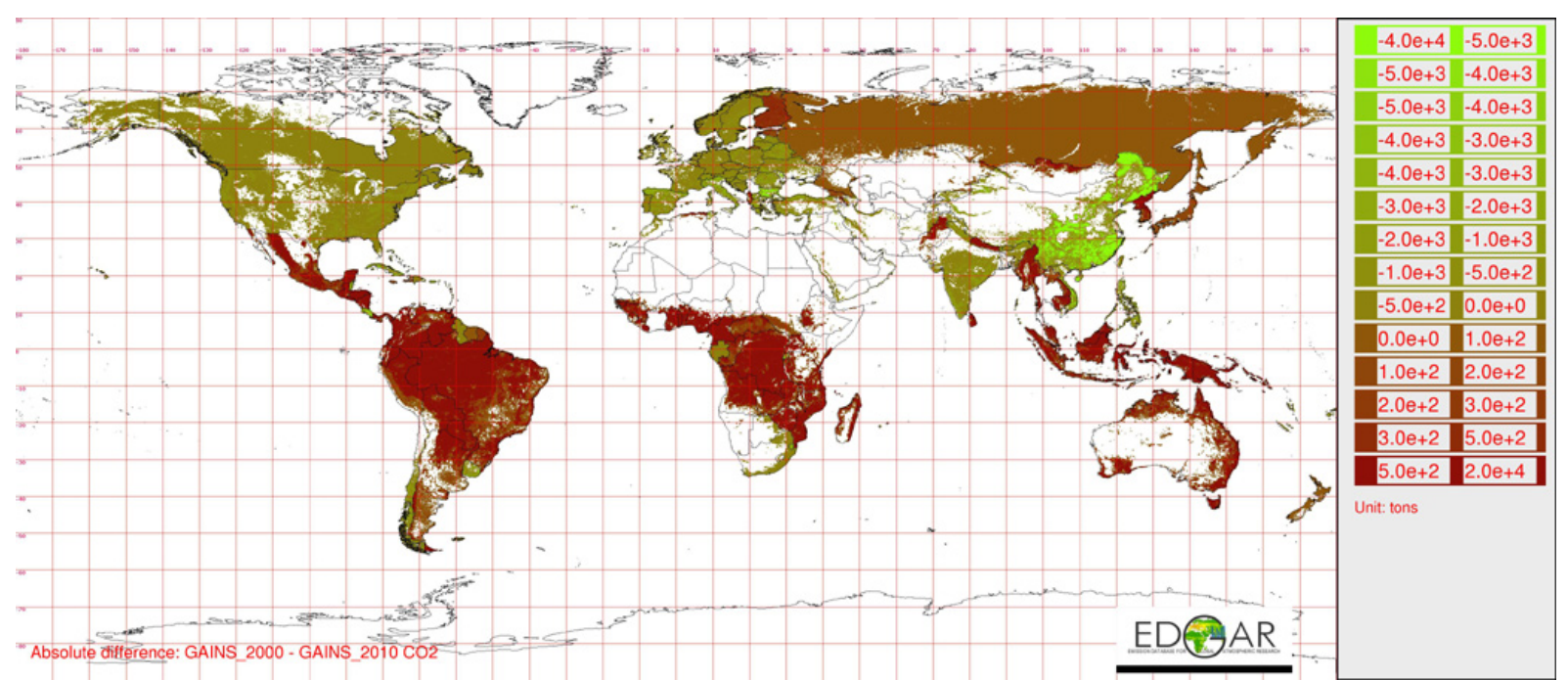

Fig. 6. Example of EDGAR grid map $\left(0.1^{\circ} \times 0.1^{\circ}\right)$ for gains in tons of $\mathrm{CO}_{2}$, representing the absolute difference between 2000 and 2010 , where positive values represent a higher $\mathrm{CO}_{2}$ removal in 2000 compared to 2010 and negative values show an increase in $\mathrm{CO}_{2}$ removal for 2010 compared to 2000 .

The main regions which contribute to the total increase in C stock are Europe, Russia and North America. Despite that $\mathrm{C}$ stock change factor values are expected to be similar for all geographical regions under similar ecological conditions, the differences among countries are generated by the countryspecific forestry practices (i.e. intensity of the management, harvest size, harvest structure on species, disturbances). Major impact on the forest growth is also given by the age structure of the forests and artificial or natural origins of forest growth (with plantations showing much higher growth rates). Especially for Non-Annex I Parties, the definitions of "increment" are generally not very transparent, which may create artefacts in building default values or estimates. This may be because of unclear inclusion of post-disturbances effects or parameters reported (i.e. current vs. average or principal vs. total forest stand increment/stock).

\subsubsection{Carbon losses in living forest biomass - harvest}

Wood harvest remains one of the most uncertain statistics at global level, which obviously affects any attempt to estimate GHG from it. For example, in the majority of Annex I Parties, i.e. the EU/EFTA group, the amount of wood resulting from unregistered cuttings contributed $16 \%$ to the overall forestrelated wood consumption between 1987 and 2005 (Mantau et al., 2007).

From Fig. 3 we notice that the differences between $C$ stock losses due to harvest are minor. The input harvest data were taken from the ForesSTAT (FAO, FAOSTAT 2011) statistics and are the same for the two approaches. Both computation methodologies use similar methods (Supplement, Eqs. 4 and 12). There is nevertheless a difference $(\sim 9 \%)$, which is likely due to the use of wood density $(D)$, which in IPCC GPG-LULUCF 2003 is set as an independent value from the biomass expansion factor of merchantable volume, BEF2 (see Supplement, Table S2), whereas in IPCC 2006 it is included in the biomass conversion and expansion factor (BCEF). Vis-à-vis BEF2 and BCEF we have to mention that losses from harvest were computed by applying these two parameters separately to roundwood and fuelwood to reflect better the case of developing countries (Non-Annex I Parties). We consider that applying BEF2 (in the context of IPCC GPG-LULUCF 2003 methodology) to each of them is conservative and the risk to underestimate emissions is minimal. This may not be the case for developed countries, where wood is more efficiently used (part of the tree goes to industry, the other part to fuelwood) and for which our computation may overestimate the emissions (nevertheless, for these there are national GHG inventories available that provide better estimates). Again, we underline that EDGAR's aim is to provide a consistent global picture of emissions.

Regarding the BCEF factor, another very important difference was found to be its allocation to major climatic zones and forest types and the fact that it is dependent on the growing stock (see IPCC, 2006, Vol. 4, Table 4.5). The growing stock was taken from the FRA (2010) country reports, estimated for the year 2005 (FRA, 2010). The stratification in IPCC GPG-LULUCF 2003 is poor compared to IPCC 2006, where more vegetation types have been introduced, decreasing in this way the uncertainty of using and allocating the parameters according to related climate zones and vegetation types (Table 2). The major regions which show an abrupt decrease in C stock because of the harvest are South and Southeast Asia, Africa and South America. Another small difference in calculations is caused by the percentage applied for conversion of FAO statistical roundwood under bark 
into merchantable wood removals over bark. In a calculation based on IPCC GPG-LULUCF 2003, we applied $12 \%$, while for IPCC $200615 \%$ (IPCC, 2006). It is easy to notice that the regions with intensive harvest have also the smallest increase in biomass growth (Fig. 3), while net deforestation adds up and plays an important role in the $\mathrm{C}$ losses (see Fig. 5).

\subsubsection{Carbon losses in living forest biomass - net deforestation}

The changes from net deforestation were calculated based on the stock change method. The difference between forest areas in 1990-2000, 2000-2005 and 2005-2010 divided by the respective number of years and multiplied with the average above-ground biomass stock allowed us to account with high assumptions for net losses from deforestation. The uncertainty around this approach is that a constant forest area does not guarantee that there is no deforestation (i.e. "shifts" of areas), as this may have been compensated by an equal afforestation. That makes simple statistics of forest or forest land area to include suitable parameters from a resource assessment point of view, but insufficient for a national GHG inventory. The difference in using the above-ground biomass stocks as global average is $\sim 27 \%$ between the two IPCC methods.

Presuming that the changes in area are correct (we calculated the increase/decrease in area based on FRA (2010) area changes with respect to the year 2000, the base year for the GLC map) and assuming that the information from the maps used for 2000 applies also for the other years, we notice (Fig. 5) that the most affected regions by deforestation over the whole period are South America and Africa, while South and Southeast Asia losses decreased in 20052010 with respect to 1990-2000. According to Friedlingstein et al. (2010), steadily increasing temperate forest regrowth in Eurasia has been observed since 2000 in these latitudes. A recent decrease in land-use change emissions is consistent with the reported downward trends of deforestation detected from satellite data in the Brazilian Amazon (Regalado, 2010) and Indonesia (Hansen et al., 2009).

It should be noted that our approach is not a dynamic estimate, accounting for long-term effects of fires and post-burn effects on the $\mathrm{C}$ gain/loss from year to year. Forest expansion was also not addressed in this study, and we preferred not to apply any such correction, because we consider that there is always an adjustment of area with previously harvested areas within a delay given by the detection thresholds, and this allows for not underestimating the emission from deforestation (under not truly known deforestation trend). On the other hand, deforestation area is not overestimated, since we use 5-yr data estimation intervals. Diseases are also not included in losses, assuming they also have a local and isolated effect. To this the assumption is added that for forest land where forest cover is permanent, change in other $\mathrm{C}$ pools is rather insignificant on a medium to long term at a large scale.
Smaller differences are noticed due to a similar classification of eco-zones and forest types for the above-ground biomass stock which is used in calculating the net deforestation (see Supplement, Table S3).

\section{Conclusions}

The aim of the current study was to estimate consistently for all countries of the world the carbon (C) stock changes from living forest biomass, in order to complete the LULUCF sector in EDGAR. For a harmonised approach allowing to derive comparable estimates for developing and developed countries, the application of the same globally applicable methodology is crucial. With the poor statistics in particular for developing countries and the internationally accepted UNFCCC methodologies, no other choice than Tier 1 level from either the IPCC GPG-LULUCF 2003 or the IPCC 2006 Guidelines is left. At global level, the estimates obtained with the two sets of guidance differed by about $40 \%$, mainly due to different ways to include roots in calculation and partly due to differences in default factors (i.e. BEF2, BECF, wood density, above-ground biomass) and ecological zones. We conclude that IPCC 2006 suits best the needs of EDGAR. It treats roots in a more consistent way, includes more updated default values and a more detailed disaggregation of the ecological zones. Our results illustrate the applicability of IPCC guidelines at a lower tier together with their shortcomings, including:

- The IPCC default values introduce high uncertainties due to the "globalization" of parameters. When the results using IPCC 2006 for Annex I Parties are compared to other international datasets (UNFCCC, FAO) or scientific publications, a significant overestimation of the sink emerges. This is likely to be mainly due to the high default values for the "gain" component (i.e. forest growth) and to the fact that we work with both unmanaged/managed forest area.

- For developing countries, our approach unavoidably led to an overlap of emissions estimated with the gainloss method (for forest remaining forest) and with the stock change method (for net changes of forest areas). A consequence of this is that the emissions from forest degradation in developing countries can hardly be estimated with the Tier 1 method, because harvest data of these countries usually do not separate harvest of forest remaining forest from the harvest of deforestation. In the context of the future mechanism to reduce emission from deforestation and forest degradation (REDD), alternative ways to estimate emissions from degradation should be foreseen for those countries not capable of implementing higher tiers. 
Overall, our work (i) highlights that the use of different IPCC guidance leads to different results, and (ii) provides a consistent global picture of $\mathrm{C}$ stock changes from living forest biomass independent of country estimates, which will be integrated in the forthcoming EDGARv4.3 time series 19902010.

\section{Supplementary material related to this article is available online at: http://www.biogeosciences.net/9/ 3437/2012/bg-9-3437-2012-supplement.pdf.}

Acknowledgements. I would like to thank all my co-authors for their support and precious comments on earlier drafts of this paper, thanks to my EDGAR team colleagues Diego Guizzardi and Valerio Pagliari for their technical support and the reviewers and editor for their thoughtful suggestions.

Edited by: F. Carswell

\section{References}

EC-JRC/PBL. EDGAR version 4.2.: available at: http://edgar.jrc.ec. europa.eu, 2011.

FAO, FAOSTAT: available at: http://faostat.fao.org/site/626/default. aspx\#ancor (last access: December 2011), updated 29 July 2011.

FAO, Global Forest Resources Assessments, FRA: http://www.fao. org/forestry/fra/fra2010/en/ (last access: December 2011), 2010.

FAO FRA 2000: http://www.fao.org/docrep/006/ad652e/ad652e00. htm\#TopOfPage (last access: March 2012), 2010.

Friedlingstein, P., Houghton, R. A., Marland, G., Hackler, J., Boden, T. A., Conway, T. J., Canadell, J. G., Raupach, M. R., Ciais, P., and Le Quéré, C.: Update on $\mathrm{CO}_{2}$ emissions, Nat. Geosci., 3, 811-812, doi:10.1038/ngeo1022, 2010.

Fritz, S. and See, L.: Comparison of land cover maps using fuzzy agreement, Int. J. Geogr. Inf. Sci., 19, 787-807, 2005.

Fritz, S. and See, L.: Identifying and quantifying uncertainty and spatial disagreement in the comparison of Global Land Cover for different applications, Glob. Change Biol., 14, 1057-1075, doi:10.1111/j.1365-2486.2007.01519.x, 2008.

GLC: Global Land Cover 2000 database. European Commission, Joint Research Centre, available at: http://bioval.jrc.ec.europa. eu/products/glc2000/glc2000.php (last access: November 2011), 2003.

Global Fire Emissions Database version 3 (GFED3): available at: http://www.falw.vu/ gwerf/GFED/index.html, last access: January 2012.

Greenough, J. A., Apps, M. J., and Kurz, W. A.: Influence of methodology and assumptions on reported national carbon flux inventories: an illustration from the Canadian forest sector, Mitigation Adapt. Strategies Global Change, 2, 267-283, 1997.

Hansen, M. C., Stehman, S. V., Potapov, P. V., Arunarwati, B., Stollem, F., and Pittman, K.: Quantifying changes in the rates of forest clearing in Indonesia fropm 1990 to 2005 using remotely sensed data sets, Environ. Res. Lett., 4, 034001, doi:10.1088/1748-9326/4/3/034001, 2009.
Hodges, J.: MODIS MOD12 Land Cover and Land Cover Dynamics Products User Guide, Department of Geography, Boston University, available at: http://geography.bu.edu/ landcover/userguidelc/lc.html (last access: October 2011), 2002.

Houghton, R. A.: Terrestrial carbon sinks-uncertain explanations, Biologist, 49, 155-160, 2002.

Houghton, R. A.: How well do we know the flux of $\mathrm{CO}_{2}$ from land use change?, Tellus B, 62, 337-351, 2010.

Holdridge, L. R.: Determination of world plant formations from simple climatic data, Science, 105, 367-368, 1947.

IPCC 2003: Good Practice Guidance for Land Use, Land-Use Change and Forestry (GPG-LULUCF), edited by: Penman, J., Gytarsky, M., Krug, T., Kruger, D., Pipatti, R., Buendia, L., Miwa, K., Ngara, T., Tanabe, K., and Wagner, F., IPCC-IGES, Kanagawa, available at: http://www.ipcc-nggip.iges.or.jp/public/ gpglulucf/gpglulucf_contents.html (last access: January 2012), 2003.

IPCC: Guidelines for national greenhouse gas inventories - volume 4: Agriculture, land use and forestry (GLAFOLU), available at: http://www.ipcc-nggip.iges.or.jp/public/ 2006gl/vol4.html (last access: January 2012), 2006.

Iverson, L., Brown, S., Prasad, A., Mitasova, H., Gillespie, A. J. R., and Lugo, A. E.: Use of GIS for estimating potential and actual forest biomass for continental South and Southeast Asia, in: Effects of Land-Use Change on Atmospheric $\mathrm{CO}_{2}$ Concentrations: South and Southeast Asia as a Case Study, edited by: Dale, V., 67-116, Springer-Verlag, New York, 1994.

Köppen, W.: Grundrisse der Klimakunde, Walter de Gruyter Co. Berlin, 1931.

Lu, A., Yao, T., and Liu, S.: Glacier change in the Geladandong Area of the Tibetan Plateau monitored by remote sensing, J. Glaciol. Geocryol., 24, 559-562, 2002.

Mantau, U., Steierer, F., Hetsch, S., and Prins, K.: Wood resources availability and demands - implications of renewable energy policies. A first glance at 2005, 2010 and 2020 in European countries, UNECE-FAO, University Hamburg, European Commission, available at: http://www.metsateho.fi/files/metsateho/ tiedote/Tiedote_07_2008_Wood_availability_and_demands.pdf (last access: December 2011), 2007.

Olofsson, P., Woodcock, C., Baccini, A., Houghton, R. A., Ozdogan, M., Gancz, V., Blujdea, V., Torchinava, P., Tufekcioglu, A., and Baskent, E. Z.: The effects of land use change on terrestrial carbon dynamics in the Black Sea region, in: Regional Aspects of Climate-Terrestrial-Hydrologic Interactions in Non-boreal Eastern Europe, edited by: Groisman, P. A. and Ivanov, S. V., Series: NATO Science for Peace and Security Series C: Environmental Security, 4, 175-182, doi:10.1007/978-90-481-2283-7_19, 2009.

Pan, Y., Birdsey, R. A., Fang, J., Houghton, R., Kauppi, P. E., Kurz, W. A., Phillips, O. L., Shvidenko, A., Lewis, S. L., Canadell, J. G., Ciais, P., Jackson, R. B., Pacala, S., McGuire, A. D., Piao, S., Rautiainen, A., Sitch, S., Hayes, D.: A large and persistent carbon sink in the world's forests, Science, 333, 988-993, doi:10.1126/science.1201609, 2011.

Preto, G.: A Proposal for the Preparation of the Global Eco-floristic Map for FRA2000, FAO, Rome, unpublished, 1998.

Regalado, A.: Brazil says rate of Deforestation in Amazon Continues to Plunge, Science, 329, 1270-1271, doi:10.1126/science.329.5997.1270-b, 2010. 
Trewartha, G. T.: An introduction to climate, Fourth Edition, McGraw-Hill, New York, 1968.

UNFCCC: The Marrakesh Accords and The Marrakesh declaration, advance text, available at: http://unfccc.int/cop7/documents/ accords_draft.pdf, (last access: January 2012), 2001.

UNFCCC National Inventory Submissions, Common Reporting Format: http://unfccc.int/national_reports/annex_i_ghg_ inventories/national_inventories_submissions/items/5888.php, (last access: January 2012), 2011. van der Werf, G. R., Randerson, J. T., Giglio, L., Collatz, G. J., Mu, M., Kasibhatla, P. S., Morton, D. C., DeFries, R. S., Jin, Y., and van Leeuwen, T. T.: Global fire emissions and the contribution of deforestation, savanna, forest, agricultural, and peat fires (19972009), Atmos. Chem. Phys., 10, 11707-11735, doi:10.5194/acp10-11707-2010, 2010.

Zhu, Z.: Develop a new Global Ecological Zone Map for GFRA2000, FAO, Rome unpublished, 1997. 